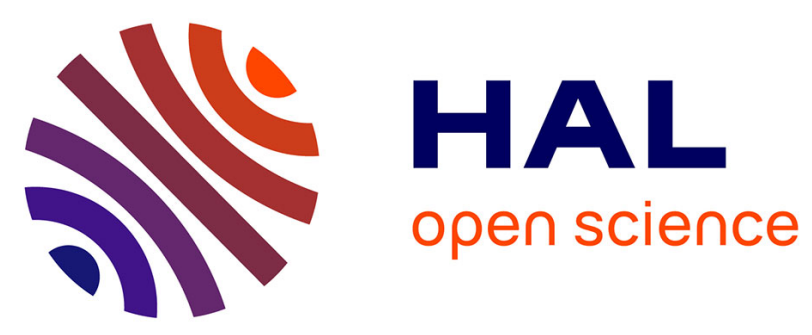

\title{
Carbon dioxide plasma treated PVDF electrospun membrane for the removal of crystal violet dyes and iron oxide nanoparticles from water
}

Deepu Gopakumar, Vishnu Arumukhan, Rogerio Gelamo, Daniel Pasquini, Luis Carlos de Morais, Samsul Rizal, D. Hermawan, Ange Nzihou, H.P.S

Abdul Khalil

\section{To cite this version:}

Deepu Gopakumar, Vishnu Arumukhan, Rogerio Gelamo, Daniel Pasquini, Luis Carlos de Morais, et al.. Carbon dioxide plasma treated PVDF electrospun membrane for the removal of crystal violet dyes and iron oxide nanoparticles from water. Nano-Structures and Nano-Objects, 2019, 18, pp.100268. 10.1016/j.nanoso.2019.100268 . hal-02079493

\section{HAL Id: hal-02079493 https://imt-mines-albi.hal.science/hal-02079493}

Submitted on 26 Mar 2019

HAL is a multi-disciplinary open access archive for the deposit and dissemination of scientific research documents, whether they are published or not. The documents may come from teaching and research institutions in France or abroad, or from public or private research centers.
L'archive ouverte pluridisciplinaire HAL, est destinée au dépôt et à la diffusion de documents scientifiques de niveau recherche, publiés ou non, émanant des établissements d'enseignement et de recherche français ou étrangers, des laboratoires publics ou privés. 


\title{
Carbon dioxide plasma treated PVDF electrospun membrane for the removal of crystal violet dyes and iron oxide nanoparticles from water
}

\author{
Deepu A. Gopakumar ${ }^{\text {a,* }}$, Vishnu Arumukhan ${ }^{\text {b }}$, Rogerio V. Gelamo ${ }^{c}$, Daniel Pasquini ${ }^{\mathrm{d}}$, \\ Luis Carlos de Morais ${ }^{\mathrm{e}}$, Samsul Rizal ${ }^{\mathrm{f}}$, D. Hermawan ${ }^{\mathrm{g}}$, Ange Nzihou ${ }^{\mathrm{h}}$, H.P.S Abdul Khalil ${ }^{\mathrm{a}, *}$ \\ a School of Industrial Technology, Universiti Sains Malaysia, Penang 11800, Malaysia \\ ${ }^{\mathrm{b}}$ Department of Chemistry and Chemical Engineering, Chalmers University of Technology, Kemigården 4, 41296 Göteborg, Sweden \\ ${ }^{c}$ Federal University of Triângulo Mineiro - UFTM, Institute of Technological and Exact Sciences, 38064-200, Uberaba, MG, Brazil \\ ${ }^{d}$ Chemistry Institute, Federal University of Uberlandia-UFU, Campus Santa Monica-Bloco1D-CP 593, 38400-902 Uberlandia, Brazil \\ e Universidade Federal do Triângulo Mineiro (UFTM), Av. Doutor Randolfo Borges, 1400, Secretaria do ICENE - SALA 109, Uberaba, MG, Brazil \\ ${ }^{\mathrm{f}}$ Mechanical Engineering Department, Universitas Syiah Kuala, Darussalam, Banda Aceh 23111, Indonesia \\ ${ }^{g}$ Department of Forestry, Kampus IPB, Darmaga, Bogor Agricultural University, Bogor 16001, West Java, Indonesia \\ ${ }^{\mathrm{h}}$ Université de Toulouse, IMT Mines Albi, RAPSODEE CNRS UMR-5302, Campus Jarlard, F-81013 Albi cedex, 09, France
}

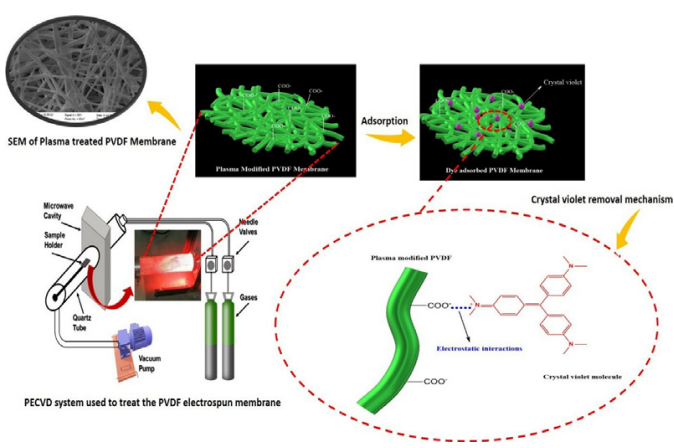

Keywords:

PVDF electrospun membrane

Carbon dioxide plasma

Dye adsorption

Nanoparticle removal

Water purification

\section{A B S T R A C T}

Here we reported a reactive plasma treatment of polyvinylidene fluoride (PVDF) electrospun membrane by using carbon dioxide $\left(\mathrm{CO}_{2}\right)$ plasma in order to reduce the hydrophobicity of the PVDF membrane and thereby used to remove toxic crystal violet dye (CV) and iron oxide $\left(\mathrm{Fe}_{2} \mathrm{O}_{3}\right)$ nanoparticles from water. The demonstrated plasma treated PVDF electrospun membrane showed a decrement in the hydrophobicity after plasma treatment. Most of the microfiltration membranes based on PVDF were fabricated via phase inversion technique and solvent casting. The main drawback of these methods is that to obtain membranes with uniform pore size. Moreover, the membranes fabricated via phase inversion and solvent casting process have low surface area whereas in the membranes via electrospinning technique have interconnected pore structure with high surface area and uniform pore size. The contact angle of the neat PVDF electrospun membrane and plasma treated PVDF electrospun membrane were $141^{\circ}$ and $102^{\circ}$ respectively. FTIR studies revealed that, after $\mathrm{CO}_{2}$ plasma treatment, highly negative carboxylate (COO-) groups were formed on the surface of the PVDF electrospun membrane. With the $10 \mathrm{mg} / \mathrm{L}$ of crystal violet $(\mathrm{CV})$ aqueous solution, the dye adsorption capacity was $1.368 \mathrm{mg} / \mathrm{g}$ of the membrane for neat PVDF membrane and $3.84 \mathrm{mg} / \mathrm{g}$ of the membrane for plasma treated PVDF membrane. It was found that, the $\mathrm{CO}_{2}$ plasma treated PVDF membrane had two- or threetimes greater adsorption capacity then neat PVDF membrane against crystal violet dyes which was due to the strong electrostatic interaction between the highly negative carboxyl groups on the surface of

\footnotetext{
* Corresponding authors.

E-mail addresses: deepu1789@gmail.com (D.A. Gopakumar), akhalilhps@gmail.com (H.P.S.A. Khalil).
} 
plasma treated PVDF electrospun membrane and protonated CV dye. Both neat PVDF membrane and plasma treated PVDF membrane showed excellent filtration capacity against $\mathrm{Fe}_{2} \mathrm{O}_{3}$ nanoparticles. The demonstrated plasma treated PVDF membrane could successfully remove iron oxide nanoparticles and crystal violet dyes from water via size exclusion and adsorption mechanism respectively.

\section{Introduction}

Water is an essential requirement for all the living organisms in earth. With the expansion of various industries, water contamination is enhancing drastically day-to-day. The release of the various toxic textile dyes from industries into water is exponentially increasing [1]. Pollution of the ground and surface water due to the textile dyes is a serious environmental threat especially to humankind and aquatic life [2-5]. Due to the growing use of dyes, the dye wastewater is fetching an environmental threat, and the removal of these pollutants from wastewater is challenging [6]. Therefore, it is paramount to develop efficient water purification media to address this issue. Favorably, membrane separation technology is one of the promising techniques to eliminate the impurities from water, where the filtration efficiency is mainly influenced by hydrophobicity, hydrophilicity, porosity surface charge etc of the membrane [7]. The commercial membranes like nanofiltration and conventional membranes are porous in nature and typically produced via phase immersion method, where it is very difficult to achieve the uniform porosity which resulted in the lower water flux [8-10]. With the development of the electrospinning technique, most of the synthetic polymer nanofibers have been applied extensively into diverse research fields and industries like air purification, gas storage , drug delivery, sensors, tissue engineering and electrodes for use in electronics [11-16]. During the electrospinning process, when the applied voltage is strong enough to overcome the surface tension of the (charged) polymer solution at the tip of the spinneret, a fine jet stream is ejected. As this jet stream travels from the spinneret to the collector, the solvent in the jet stream is evaporated while the polymer solution begins to form a thinner and thinner jet stream, resulting in the formation of a non-woven fibrous scaffold at the collector [17]. The fiber diameter and the morphology are affected by both processing and materials parameters. A relatively new utilization of the electrospun nanofibrous scaffolds is their application in water purification $[8,18-20]$.

Electrospun membranes have a high porosity $(<80 \%)$ with fine diameters (from about $0.1 \mu \mathrm{m} \mathrm{m}$ to about $1 \mu \mathrm{m}$ ) and an interconnected-pore structure, which yields a relatively very high specific surface area. Newly, electrospun based membrane materials with good water flux has been attained a considerable attention in membrane separation technology especially in nanofiltration and ultrafiltration applications due to their fascinating specific surface area, excellent interconnectivity of fibers and uniform porosity with 3D nanofibrous structure [17,21,22]. Recently, electrospinning technique has been applied to diverse polymers to fabricate uniform 3D porous water filtration membranes having fiber diameters ranging from nanometers to micrometers could be controlled via different processing parameters like surface tension, applied voltage, concentration of solution, applied voltage, flow rate etc. So far, a lot of literatures have been reported on the removal of organic pollutants from water [2335]. Among the fluoropolymers, PVDF has gained considerable attention as an excellent membrane material due to its fascinating properties like chemical resistance against base, acids and solvents, mechanically robust, excellent thermal stability etc. In addition to this, PVDF could be easily dissolve in almost organic solvents. These above mentioned properties of PVDF suggests it as an efficient filter membrane for water treatment [36-39]. Primarily, hydrophobic membranes are more prone to membrane fouling in contrast to hydrophilic membranes which could be attributed to the hydrophobic interaction between membrane materials, solutes and microbial cells [40]. Moreover, the adsorption of organic species, the precipitation of less soluble inorganic species and adhesion of microbial cells also resulted in the membrane fouling [41]. It is well known that the membrane fouling is higher for hydrophobic membranes than hydrophilic ones. A few literatures have been reported on the PVDF based membranes for dye removal. Gopakumar et al. [15] reported Meldrum's acid modified CNF based PVDF membrane for the removal of crystal violet and they removed $3.98 \mathrm{mg} / \mathrm{g}$ of membrane of Crystal violet dye from water [15] . Similarly, Gopi et al. [42] also removed indigo carmine dye using chitin nanowhisker-functionalized electrospun PVDF membrane and they achieved a removal efficiency of $88.9 \%$ against indigo carmine dyes [42]. In most of the abovementioned works, a surface modified poly saccharide material was employed to coat over the PVDF electrospun membrane which are very difficult to commercialize at the industrial level. Some works have been reported on the removal of dyes using PVDF based blend membranes. Srivastava et al. [43] reported on the PVDF/SAN blend membrane for the removal of reactive black (RB5) and congo red (CR) from water and the fabricated membrane removed $97 \%$ of $C R$ dye and $70 \%$ of RB5 dye from the feed solution [43]. The other work was reported by Nikooe et al. [44] and they removed reactive red dye 141 by using PVDF/Brij-58 surfactant blend nanofiltration membrane [44]. Recently, Surface modification using Reactive Plasma treatment has been shown an excellent technique for polymer treatment for a few reasons. Plasma treated membranes have been used widely in water treatment, biomedical, pharmaceutical, food and gas separation industries. Reactive Plasma Process can activate only the upper layer of the membrane not affecting the bulk properties of the polymer [45-47]. Additionally, this technique is versatile since by controlling some system variables it is possible to modify considerably the physical and chemical properties of membranes by sparing time and chemical reagents by comparing them with the techniques conventionally used in materials chemistry. Some reports have been investigated on the effect of plasma on the PVDF membranes [48-53]. Among them, a very few literatures have been reported on plasma modified PVDF membranes for dye removal. Buonomenna et al. [54] reported Argon plasma treated PVDF membrane for the removal of methylene blue and congo red but in this case, they used phase inversion process for the fabrication of PVDF membrane [54]. The main issue in the membranes which are fabricated via phase inversion process is very difficult to achieve the uniform pore size. In this context, herein we make use of $\mathrm{CO}_{2}$ plasma treatment on the PVDF electrospun membrane in order to reduce the hydrophobicity and for the removal of iron oxide nanoparticles and crystal violet dye from water. So far, this is the first report on the $\mathrm{CO}_{2}$ plasma treated PVDF electrospun membranes for removing toxic crystal violet textile dyes and iron oxide nanoparticles from water via adsorption and size exclusion mechanism respectively. 


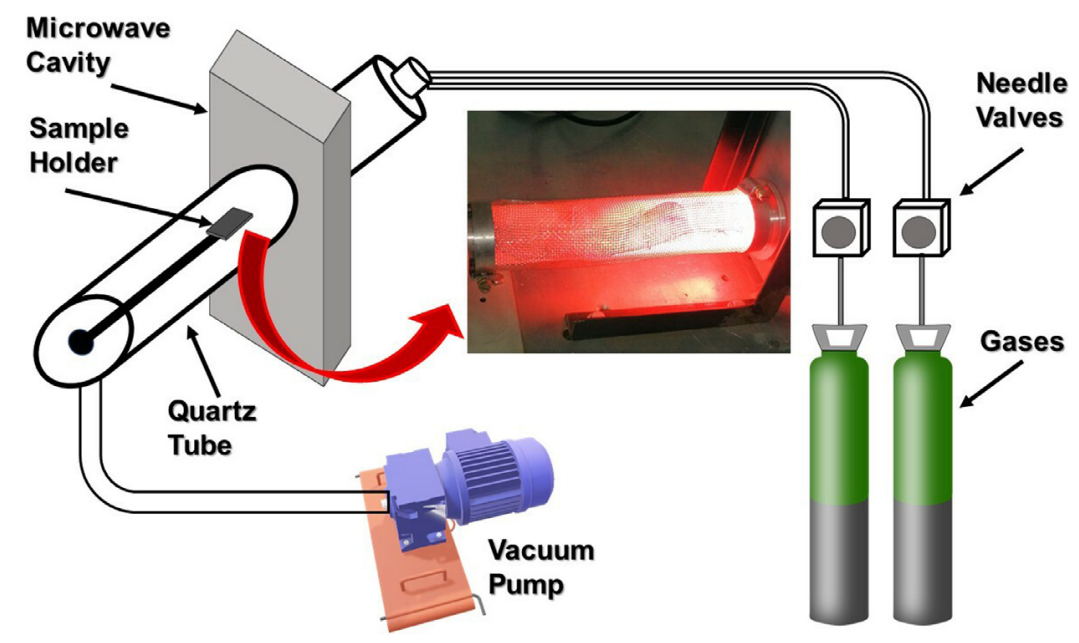

Fig. 1. Schematic representation of the PECVD system used to treat the PVDF electrospun membrane.

\section{Materials and methods}

\subsection{Materials}

PVDF with Mwt $(2,76000 \mathrm{~g} / \mathrm{mol})$ and iron oxide $\left(\mathrm{Fe}_{2} \mathrm{O}_{3}\right)$ nanoparticles in the range of $50-100 \mathrm{~nm}$ were procured from Sigma-Aldrich, Brazil. Crystal violet dye $\left(\mathrm{CV}, \mathrm{C}_{25} \mathrm{H}_{30} \mathrm{~N}_{3} \mathrm{Cl}, \lambda_{\max }=\right.$ $584 \mathrm{~nm}, \mathrm{MM}=407.89 \mathrm{~g} / \mathrm{mol}$ ) was purchased from Vetec (Brazil).

\subsection{Preparation of PVDF electrospun membrane}

Initially (Acetone/DMF) at a volume ratio of 40:60 solvent mixture was used to dissolve $17 \mathrm{wt} \%$ of PVDF pellets at $50{ }^{\circ} \mathrm{C}$. The electrospinning equipment (HOLMARC: HO-NEV-02) was employed to fabricate PVDF electrospun membrane at $15 \mathrm{KV}$ at $29^{\circ} \mathrm{C}$ with a tip to collector distance of $15 \mathrm{~cm}$ at a feed rate of $1 \mathrm{~mL} / \mathrm{h}$. In order to improve the structural integrity of the fabricated electrospun membrane and for the removal of the residual solvent from the membrane, the fabricated porous membrane was kept in a hot air oven at $140{ }^{\circ} \mathrm{C}$ for $3 \mathrm{~h}$ prior to the characterization.

\section{3. $\mathrm{CO}_{2}$ plasma treatment on the PVDF electrospun membrane}

Fig. 1 is a schematic representation of the plasma enhanced chemical vapor deposition (PECVD) system used to treat the PVDF electrospun membrane. Vacuum was performed with a rotary vane pump of $10 \mathrm{~m}^{3} / \mathrm{h}$ pumping speed (Edwards model RV8). For the plasma generation, a microwave source $(2.460 \mathrm{GHz}, 1000 \mathrm{~W})$ was used. $\mathrm{CO}_{2}$ (99.99\% pure) was mixed with Argon (99.99\% purity) during the plasma discharge. The residual pressure before gases admittance was 1.0 mTorr. The gases used in the treatment was introduced in the quartz chamber and the flux was controlled using need valve (Edwards model LV10K). In this study we used reactive plasma treatment by mixtures of $\mathrm{CO}_{2}$ and Argon to reduce the hydrophobicity of PVDF electrospun membrane. The Argon was first admitted in the chamber until the pressure of 350.0 mTorr and after, $\mathrm{CO}_{2}$ was introduced until the final pressure reached 450.0 mTorr. The sample holder with the membrane was kept at approximately $10 \mathrm{~cm}$ from the microwave source. The samples were treated for $5 \mathrm{~min}$ and at this time of treatment no appreciable increase in temperature was observed.

\subsection{Scanning Electron Microscopy}

SEM (CARL ZE ISS, EVO MA10) was used to investigate the surface morphology of the neat PVDF and plasma treated PVDF electrospun membrane. The samples were dried and sputtered with gold coating in an argon atmosphere. The samples were observed at an acceleration voltage of $20 \mathrm{KV}$.

\subsection{Fourier Transform Infrared spectroscopy}

Attenuated Total Reflection (ATR) technique was employed to obtain the IR spectra of neat PVDF membrane and plasma treated membrane from 400 to $4000 \mathrm{~cm}^{-1}$ using FTIR Agilent Technologies, Carry 600 Series FTIR Spectrometer and ATR purchase from Pike Technologies.

\subsection{Contact angle studies}

In order to obtain the water contact angles of neat PVDF and plasma treated electrospun membrane, SCA20 contact angle analyzer was employed. $10 \mu \mathrm{L}$ of distilled water was used for obtaining the water contact angle values. Five measurements were taken for each sample in order to calculate the average value.

\subsection{UV-visible spectrophotometer}

Iron oxide nanoparticle and CV dye removal were studied using UV-spectrophotometer ((FEMTO Mod. 800X I) via transmittance, absorbance respectively. The starting solution and filtrate were transferred into PMMA disposable cuvette and transmittance was obtained from 300 to $900 \mathrm{~m}$ for the assessment of the nanoparticle removal where as in the case of dye removal evaluation, the same procedure was repeated, and absorbance was measured at $590 \mathrm{~nm}$. A spectrum of cuvette with water was used as the reference for the calibration of the transmittance and absorbance of the samples. In order to obtain the solute concentrations in the feed and final solutions, UV-Vis procedure was used.

2.8. Assessment of the adsorption capacity of PVDF and plasma treated PVDF membranes against crystal violet dyes

Firstly, $0.06 \mathrm{~g}$ of plasma treated and untreated PVDF membrane was soaked in $30 \mathrm{ml}$ of $\mathrm{CV}$ solution (concentration of 


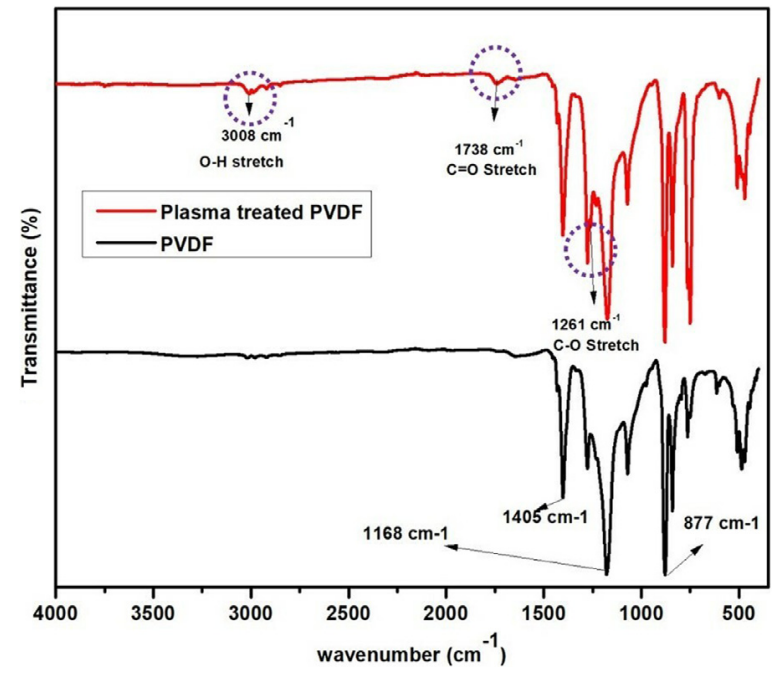

Fig. 2. SEM image of (a) neat PVDF electrospun membrane and (b) $\mathrm{CO}_{2}$ plasma treated PVDF electrospun membrane.

(10 mg CV /L)/ pH-7.0) on shaking bed for $4 \mathrm{~h}$ at room temperature. The value of the adsorption capacity of both membranes against CV dye was determined as a function of time. UV-visible spectrophotometer was employed to determine the concentration of the absorbed CV dye on to the both membranes via optical adsorption at $590 \mathrm{~nm}$.

The dye removal efficiency $(\mathrm{R} \%)$ of the fabricated $\mathrm{CO}_{2}$ plasma treated PVDF membrane was evaluated by the following equation [55].

$\mathrm{R}(\%)=\frac{C_{\mathrm{i}}-C_{0}}{C_{0}} \times 100$

Where $\mathrm{Ci}(\mathrm{mg} / \mathrm{L})$ and $\mathrm{Co}(\mathrm{mg} / \mathrm{L})$ are concentrations of crystal violet dye in the feed and final solutions respectively. These concentrations were obtained from variation of absorbance, obtained from UV-Vis spectra, versus dye concentration.

2.9. Microfiltration test of the neat PVDF membrane and plasma treated PVDF electrospun membrane

A glass filtration assembly with a filtration area of $9.5 \mathrm{~cm}^{2}$ (Holder-46 mm) was employed to conduct the microfiltration performance of both treated and untreated PVDF electrospun membranes. The feed solution was prepared by using $0.3 \mathrm{wt} \%$ of $\mathrm{Fe}_{2} \mathrm{O}_{3}$ nanoparticles in $50 \mathrm{ml}$ of distilled water via stirring at $10,000 \mathrm{rpm}$ for $10 \mathrm{~min}$ with an Ultra-turrax homogenizer (IKA T25). The filtration test was conducted using feed solution with $0.3 \mathrm{wt} \%$ of $\mathrm{Fe}_{2} \mathrm{O}_{3}$ nanoparticles in the range of $50-100 \mathrm{~nm}$ at a pressure of $200 \mathrm{~mm} \mathrm{Hg}$.

\section{Results and discussion}

\subsection{Physicochemical characterization of the membrane}

\subsubsection{FTIR Studies}

The FTIR spectra of neat PVDF membrane and $\mathrm{CO}_{2}$ plasma treated PVDF membrane are shown in Fig. 2. As shown in Fig. 2, neat PVDF membrane exhibited characteristic peaks at $1405 \mathrm{~cm}^{-1}$ and $1168 \mathrm{~cm}^{-1}$ were attributed to $\mathrm{CH}_{2}$ and $\mathrm{CF}_{2}$ stretching vibrations. Moreover, a skeletal vibration of $\mathrm{C}-\mathrm{C}$ bond was shown at $877 \mathrm{~cm}^{-1}$ [56,57]. In the case of $\mathrm{CO}_{2}$ plasma treated PVDF membrane, displayed main peaks at $1738 \mathrm{~cm}^{-1}$ and $1261 \mathrm{~cm}^{-1}$ which was due to the $\mathrm{C}=\mathrm{O}$ and $\mathrm{C}-\mathrm{O}$ stretching after $\mathrm{CO}_{2}$ plasma treatment. Additionally, a stretching of $\mathrm{O}-\mathrm{H}$ was shown at $3008 \mathrm{~cm}^{-1}$, which clearly indicates the reduction of hydrophobicity of PVDF membrane after $\mathrm{CO}_{2}$ plasma treatment.

\subsubsection{Morphology of plasma treated PVDF electrospun membrane}

The SEM images of PVDF membrane and $\mathrm{CO}_{2}$ plasma treated PVDF electrospun membrane are shown in the Figs. 3(a) and 3(b) respectively. It is clearly evident from the Figs. $3 a$ \& $3 b$, that both membranes exhibited a 3-D network of irregular arrangement of PVDF nanofibers with $700 \mathrm{~nm}$ of average fiber diameter. It could be seen that, after plasma treatment the polymer nanofibers were well interconnected and fused as shown in Fig. 3(b). Moreover, after plasma modification the surface of the PVDF membrane become smoother which resulted in the reduction of contact angle when contrast to the neat PVDF membrane. It can be concluded that, after plasma treatment, the hydrophobicity of PVDF membrane was reduced to some extent, this will reduce the fouling problem of the highly hydrophobic PVDF electrospun membrane.

\subsubsection{Contact angle studies of $P V D F$ membrane and $\mathrm{CO}_{2}$ plasma treated membrane}

The water contact angle values of both membranes were analyzed in order to investigate the wettability and fouling problem of the membrane. Generally, a highly hydrophobic membrane shows fouling problem due to the accumulation of the oil particles on the surface of the membrane due to the highly hydrophobic nature of polymer which eventually affects the water filtration performance and water flux of the membrane. The obtained water contact angles were $142.6^{\circ}$ and $102^{\circ}$ for neat PVDF membrane and $\mathrm{CO}_{2}$ plasma treated PVDF membrane respectively. It was quite interesting that, after $\mathrm{CO}_{2}$ plasma treatment, the contact angle of the PVDF membrane was reduced from $142.6^{\circ}$ to $102^{\circ}$ which indicates the better wettability and decrement in the hydrophobic nature of the PVDF membrane as shown in the Fig. 4. With the decrement in the hydrophobic nature of PVDF membrane after $\mathrm{CO}_{2}$ plasma treatment, it can be concluded that the $\mathrm{CO}_{2}$ plasma treatment could reduce the fouling issue of the membrane to some extent.

\subsection{Evaluation of membrane performance}

\subsubsection{Estimation of adsorption capacity of neat PVDF membrane} plasma treated PVDF membrane towards crystal violet dye

In order to evaluate the adsorption capacity of both membranes, UV-Vis spectroscopy was used. The absorption capacity of both PVDF and $\mathrm{CO}_{2}$ plasma treated PVDF membranes against $10 \mathrm{mg} / \mathrm{L}$ of crystal violet (CV) dye as a function of time are shown in the Fig. 5. The obtained adsorption capacities of neat PVDF membrane and $\mathrm{CO}_{2}$ plasma treated PVDF membrane were 1.367 and $3.84 \mathrm{mg} / \mathrm{g}$ of the membrane respectively. These results were proportionate with values of Ma et al., and Gopakumar et al., who reported that the absorption of crystal violet dye was $3.8 \mathrm{mg} / \mathrm{g}$ and $3.984 \mathrm{mg} / \mathrm{g}$ using cellulose nanowhiskers based Poly acrylonitrile membrane and PVDF based Meldrum's acid CNF membrane respectively [15,58]. Table 1 shows some of the reported dye removal values of PVDF based membranes. From Table 1, it is evident that the dye removal capacity of the fabricated $\mathrm{CO}_{2}$ plasma treated membrane was comparable with other reports.

It was found that, the $\mathrm{CO}_{2}$ plasma treated PVDF membrane had two- or three-times greater adsorption capacity then neat PVDF membrane against crystal violet dyes which was due to the strong electrostatic interaction between the highly negative carboxyl groups on the surface of plasma treated PVDF electrospun membrane and protonated CV dye molecule. The mechanism of 

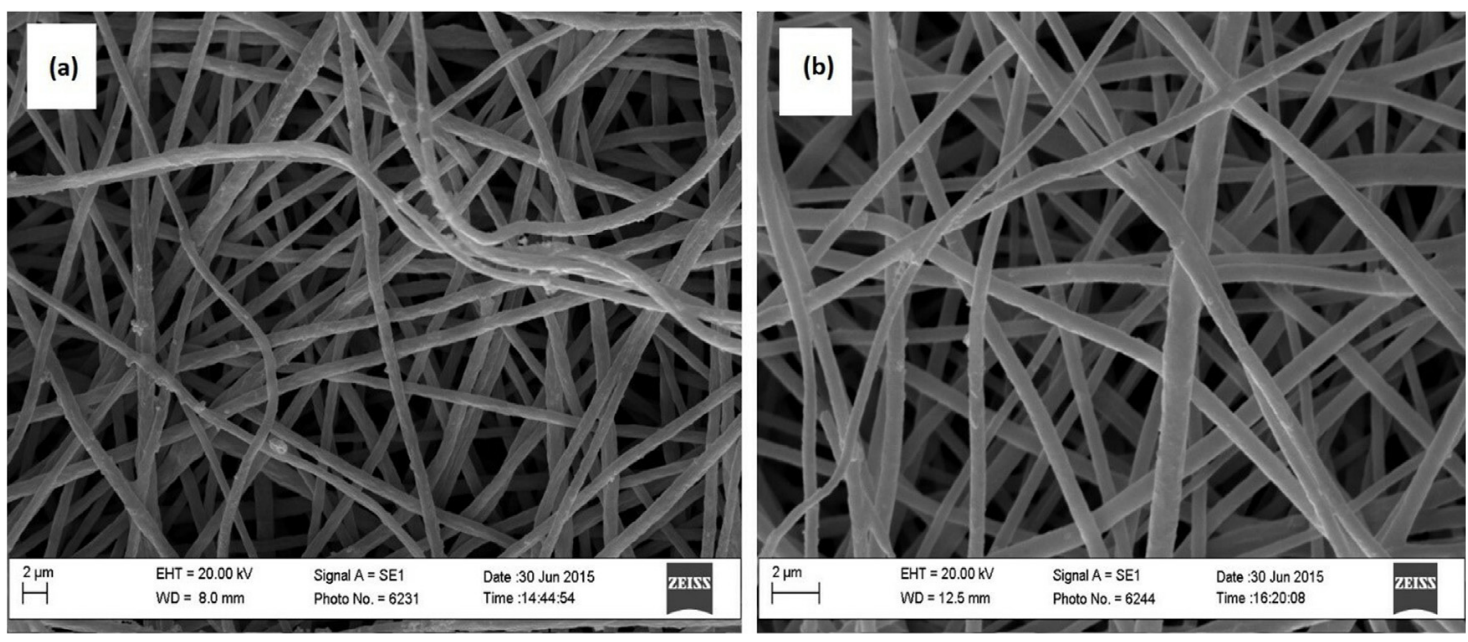

Fig. 3. FTIR spectra of neat PVDF electrospun membrane and $\mathrm{CO}_{2}$ plasma treated electrospun membrane.

Table 1

Dye removal values of some PVDF based membranes.

\begin{tabular}{lllll}
\hline Materials & Dye pollutant & Dye removal $(\mathrm{mg} / \mathrm{g})$ & Dye removal efficiency $(\%)$ & References \\
\hline PVDF based Meldrum's acid CNF membrane & Crystal violet & 3.984 & - & {$[15]$} \\
Chitin nanowhisker based PVDF membrane & Indigo carmine & - & 88.9 & {$[42]$} \\
PVDF/Brij-58 blend nanofiltration membrane & Reactive red & - & 77 & {$[44]$} \\
PVDF/ SAN membrane & Reactive black 5 & - & 70 & {$[43]$} \\
$\mathrm{CO}_{2}$ plasma treated PVDF membrane & Crystal violet & 3.84 & 87.6 & This work \\
\hline
\end{tabular}

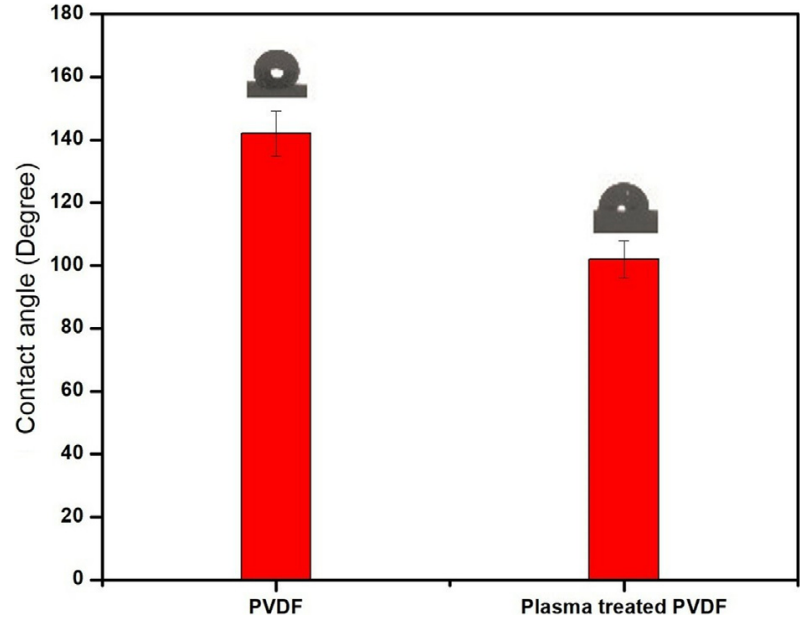

Fig. 4. Contact angles of neat PVDF electrospun membrane and $\mathrm{CO}_{2}$ plasma treated PVDF electrospun membrane.

the CV dye adsorption of the plasma treated PVDF membrane is shown in the Fig. 6 . Therefore, the demonstrated plasma treated membrane will be an effective adsorbent for the elimination of toxic textile dyes from the water.

3.2.2. Microfiltration performance of PVDF membrane and plasma treated PVDF membrane against nanoparticles

Fig. 7a \& 7b shows the upper and the lower surfaces of the neat PVDF membrane afterwards the filtration of iron oxide nanoparticles. It is shown that, after filtration against $\mathrm{Fe}_{2} \mathrm{O}_{3}$ nanoparticles, most of the nanoparticles were filtered on the upper surface of the PVDF electrospun membrane, whereas in the lower portion no trace of nanoparticles was observed. Similarly, in the case of plasma treated PVDF electrospun membrane, most of the particles were removed/ filtered on the upper surface of the

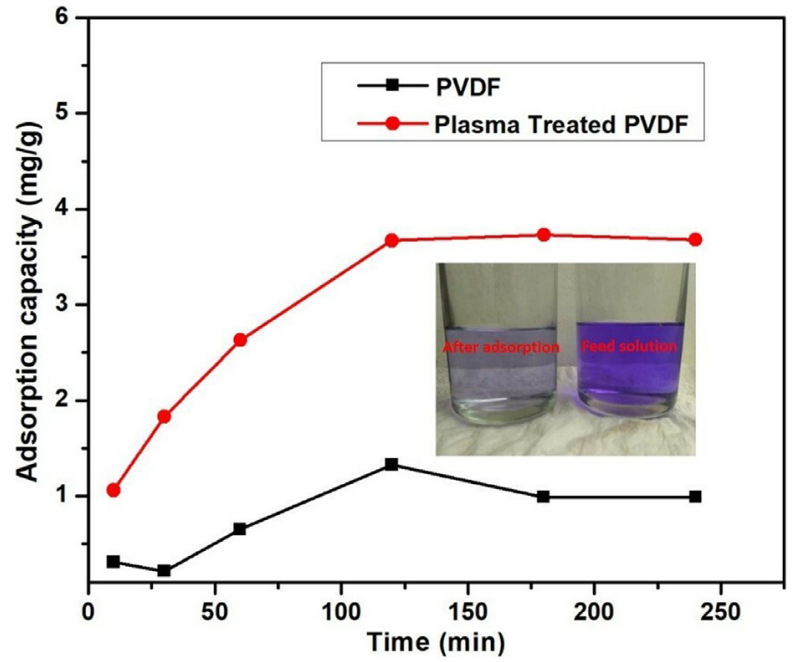

Fig. 5. Adsorption capacity of neat PVDF electrospun membrane and $\mathrm{CO}_{2}$ plasma treated PVDF electrospun membrane.

membrane while at the lower portion we could not find any trace of nanoparticles as shown in Fig. $8 \mathrm{a} \& 8 \mathrm{~b}$. These results suggest that, the both PVDF membrane and plasma treated PVDF membrane were successfully eliminate $\mathrm{Fe}_{2} \mathrm{O}_{3}$ nanoparticles from the water solution with good rejection rate of over $99 \%$. Since in this work, we focused on the plasma treated PVDF membrane, we investigated UV-visible spectra of starting and filtrate solution of plasma treated PVDF membrane against $\mathrm{Fe}_{2} \mathrm{O}_{3}$ nanoparticles as shown in the Fig. 9. From Fig. 9, it clearly shown that the fabricated plasma treated PVDF electrospun membrane had successfully removed the $\mathrm{Fe}_{2} \mathrm{O}_{3}$ nanoparticles from the feed solution with good rejection rate over $99 \%$. 

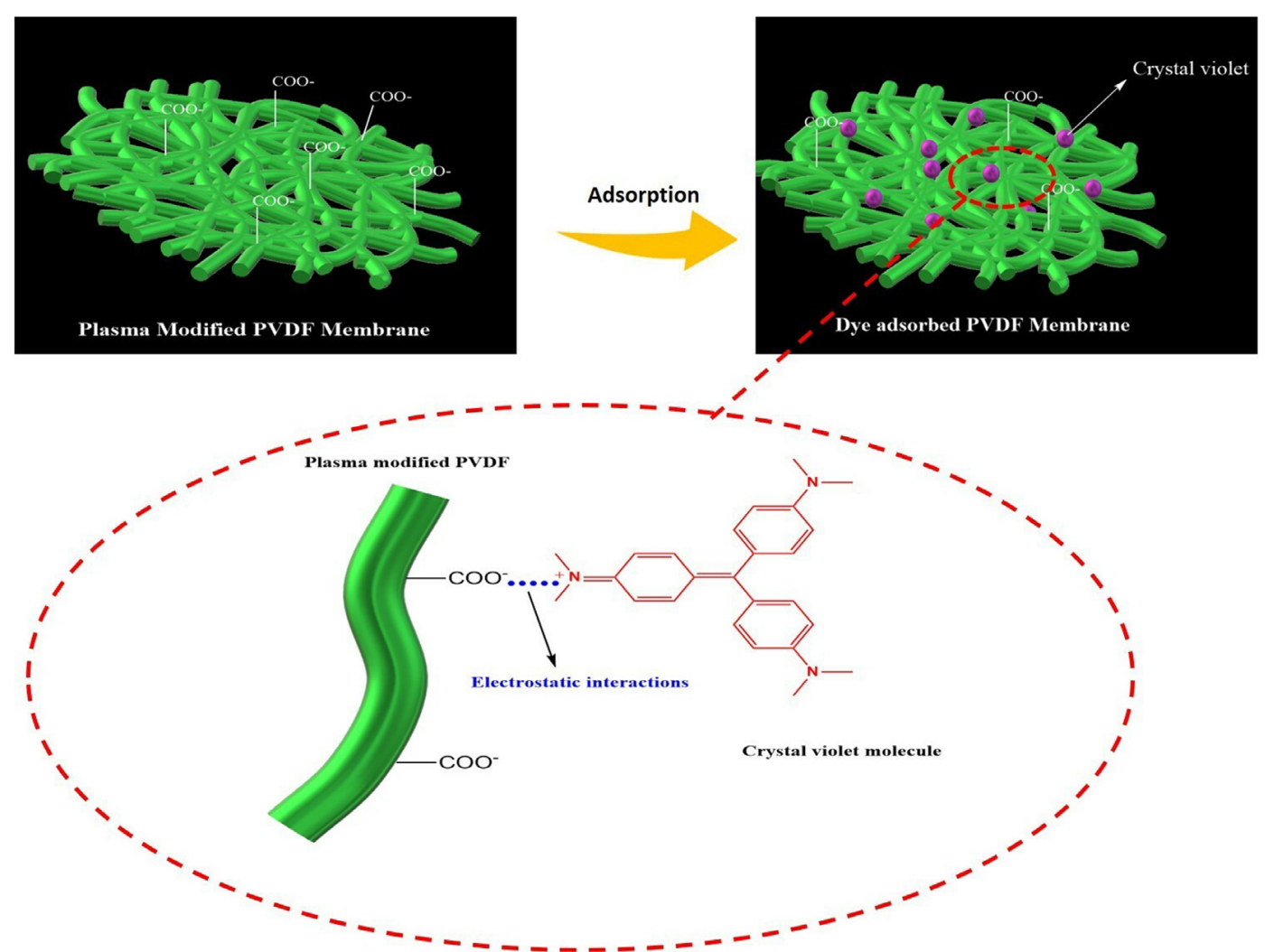

Fig. 6. Schematic picture illustrating a proposed mechanism for the removal of crystal violet dye by $\mathrm{CO}_{2}$ plasma treated PVDF electrospun membrane.
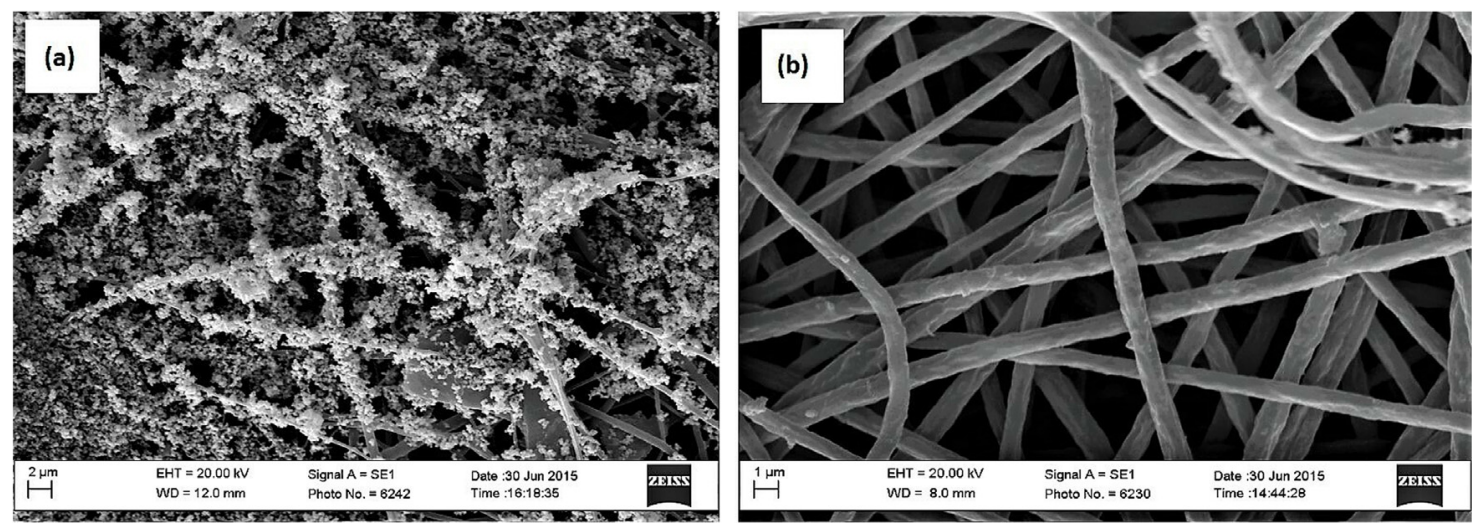

Fig. 7. SEM images of (a) top and (b) bottom portion of PVDF electrospun membrane after the filtration of iron oxide nanoparticles.
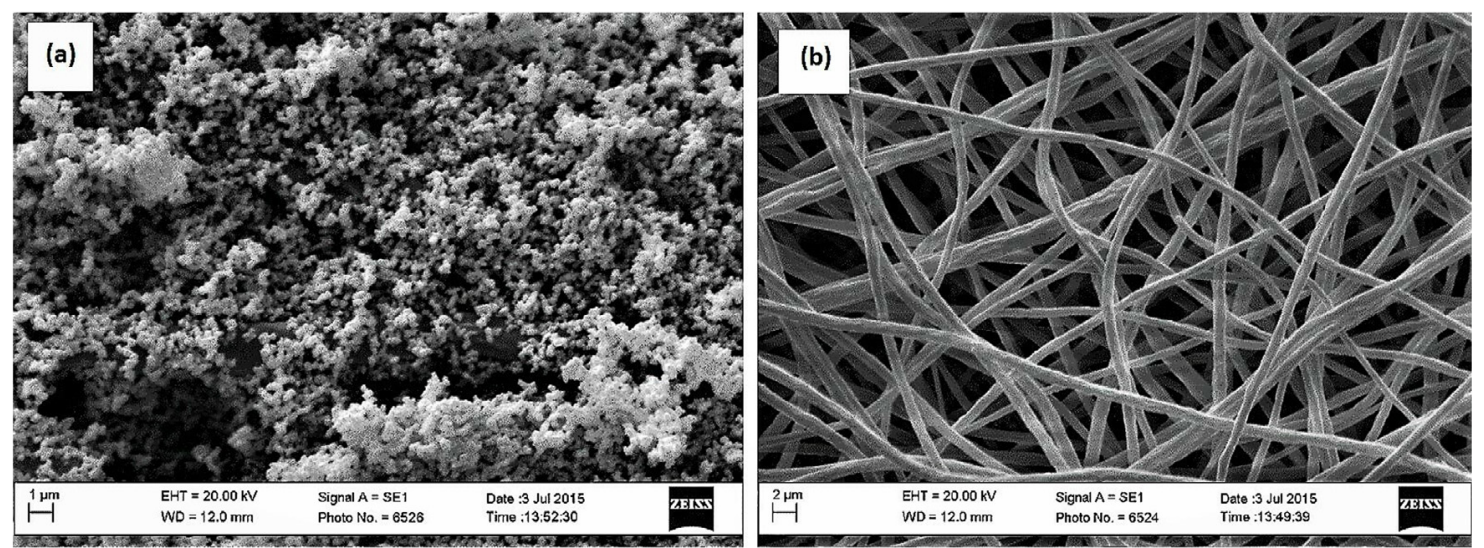

Fig. 8. SEM images of (a) top and (b) bottom portion of the plasma treated electrospun membrane after filtration of iron oxide nanoparticles. 


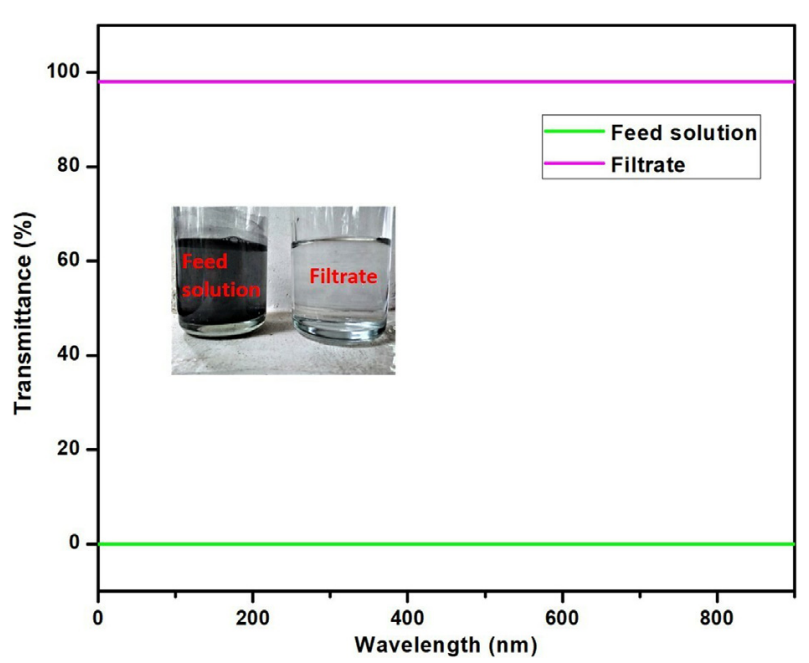

Fig. 9. UV-visible spectra of feed and filtrate solution of iron oxide nanoparticles for the $\mathrm{CO}_{2}$ plasma treated PVDF electrospun membrane.

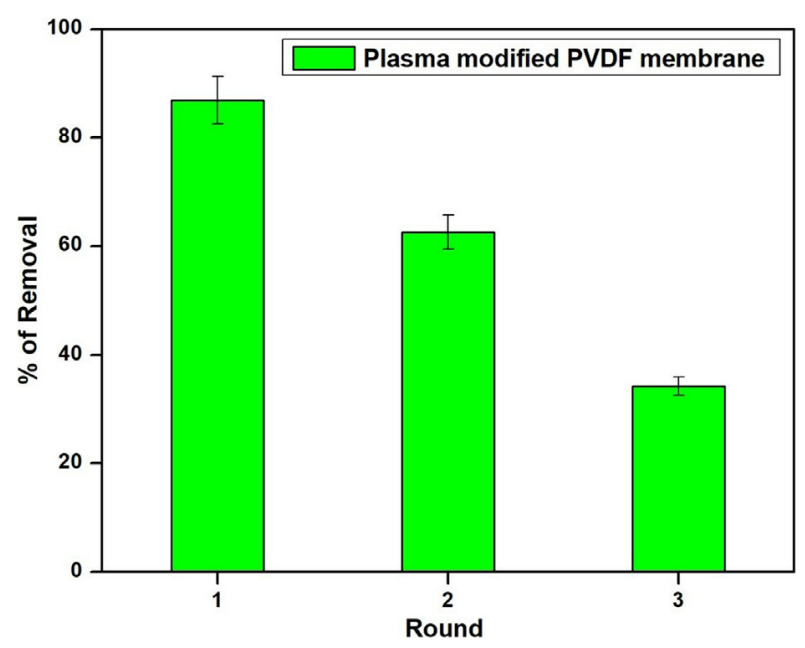

Fig. 10. Reusability study of $\mathrm{CO}_{2}$ plasma treated PVDF electrospun membrane.

\subsubsection{Reusability studies of the fabricated membrane}

In order to study the reusability of the carbon dioxide plasma modified PVDF electrospun against crystal violet dyes, plasma modified PVDF membrane was washed and dried after the first adsorption cycle in running water for $25 \mathrm{~min}$. After this, the membrane was transferred to a $200 \mathrm{~mL}$ of beaker and stirred for $3 \mathrm{~h}$. Then the cleaned plasma modified PVDF membrane was used for the second adsorption cycle. The same procedure was repeated for 3rd absorption cycle too. From the Fig. 10, it is shown that, $87.6 \%$ of removal efficiency was observed for the first adsorption cycle whereas during 2 nd adsorption cycle it was reduced to $62.8 \%$ and $33.4 \%$ for 3rd adsorption cycle. From this, it can be concluded that the reusability and removal efficiency of the fabricated plasma modified PVDF membrane is noteworthy as an absorbent material against toxic crystal violet dyes.

\section{Conclusion}

PVDF electrospun membrane was successfully fabricated via electrospinning process. $\mathrm{CO}_{2}$ plasma treatment on the fabricated PVDF electrospun membrane was successful, which reduces the contact angle of the neat PVDF membrane from $141^{\circ}$ to $102^{\circ}$. Using $10 \mathrm{mg} / \mathrm{L}$ of CV solution, the neat PVDF showed an adsorption capacity of $1.368 \mathrm{mg} / \mathrm{g}$ of the membrane, whereas in the case of the plasma treated PVDF membrane showed $3.84 \mathrm{mg} / \mathrm{g}$ of the membrane. Plasma treated PVDF membrane showed twoor three-times CV adsorption capacity than neat PVDF membrane which was due to the strong electrostatic interaction between the protonated $\mathrm{CV}$ molecules and highly negative carboxyl groups on the surface of plasma treated PVDF membrane. The fabricated membrane had good rejection rate against $\mathrm{Fe}_{2} \mathrm{O}_{3}$ nanoparticles which implies that most of the nanoparticles were entrapped on the surface of the electrospun membrane due to its 3D interconnected network pore structure which was confirmed from the SEM images. Morphology studies revealed that, after plasma treatment the surface of the PVDF electrospun membrane become more smoother compared to neat PVDF membrane. The decrement in the contact angle of the PVDF electrospun membrane after the plasma treatment will be reduced the fouling problem of the membrane to some extent. Both pristine and plasma treated PVDF membrane showed excellent filtration performance against $\mathrm{Fe}_{2} \mathrm{O}_{3}$ nanoparticles. The demonstrated plasma treated PVDF electrospun membrane could successfully eliminate the crystal violet dyes and $\mathrm{Fe}_{2} \mathrm{O}_{3}$ nanoparticles via adsorption and size exclusion mechanism respectively. So, we strongly considered that the present study will be an impressive platform to design the PVDF microfiltration membranes for the removal of water pollutants via adsorption and size exclusion mechanism in the near future.

\section{Acknowledgments}

The authors are grateful to Universiti Sains Malaysia (USM) for providing Post-Doctoral fellowship to Deepu A. Gopakumar. The authors are grateful to Capes, CNPq, Fapemig for the material support to the current study, as well as to National Institute of Science and Technology Carbon Nanomaterials - CNPq.

\section{Conflict of interest}

The paper has not been submitted to any journal and no part of the work has been published. We declare no conflict of interest.

\section{References}

[1] Y. Zhao, Q. Sun, J. Luo, H. Chen, W. Cai, X. Su, Hydrothermal fabrication of $\mathrm{TiO}_{2}-\mathrm{MoO}_{3}$ nanocomposites with superior performance for water treatment, Nano-Struct. Nano-Objects (2018) http://dx.doi.org/10.1016/j.nanoso. 2017.12.003.

[2] K. Basu, N. Nandi, B. Mondal, A. Dehsorkhi, I.W. Hamley, A. Banerjee, Peptide-based ambidextrous bifunctional gelator: applications in oil spill recovery and removal of toxic organic dyes for waste water management, Interface Focus. 7 (2017) 20160128, http://dx.doi.org/10.1098/rsfs.2016. 0128.

[3] P.A. Carneiro, G.A. Umbuzeiro, D.P. Oliveira, M.V.B. Zanoni, Assessment of water contamination caused by a mutagenic textile effluent/dyehouse effluent bearing disperse dyes, J. Hazard. Mater. 174 (2010) 694-699, http://dx.doi.org/10.1016/j.jhazmat.2009.09.106.

[4] S. Chawla, H. Uppal, M. Yadav, N. Bahadur, N. Singh, Zinc peroxide nanomaterial as an adsorbent for removal of Congo red dye from waste water, Ecotoxicol. Environ. Safety 135 (2017) 68-74, http://dx.doi.org/10. 1016/j.ecoenv.2016.09.017.

[5] N. Nandi, A. Baral, K. Basu, S. Roy, A. Banerjee, A dipeptide-based superhydrogel: Removal of toxic dyes and heavy metal ions from waste water, Biopolymers 108 (2017) http://dx.doi.org/10.1002/bip.22915.

[6] Z. Carmen, S. Daniel, Textile organic dyes - Characteristics, polluting effects and separation/elimination procedures from industrial effluents - A critical overview, in: Org. Pollut. Ten Years After Stock. Conv. - Environ. Anal. Updat., 2012, http://dx.doi.org/10.5772/32373.

[7] X. Cao, M. Huang, B. Ding, J. Yu, G. Sun, Robust polyacrylonitrile nanofibrous membrane reinforced with jute cellulose nanowhiskers for water purification, Desalination 316 (2013) 120-126, http://dx.doi.org/10.1016/j. desal.2013.01.031.

[8] K. Yoon, K. Kim, X. Wang, D. Fang, B.S. Hsiao, B. Chu, High flux ultrafiltration membranes based on electrospun nanofibrous PAN scaffolds and chitosan coating, Polymer (Guildf) 47 (2006) 2434-2441, http://dx.doi.org/ 10.1016/j.polymer.2006.01.042. 
[9] H. Ma, C. Burger, B.S. Hsiao, B. Chu, Ultrafine polysaccharide nanofibrous membranes for water purification, Biomacromolecules 12 (2011) 970-976, http://dx.doi.org/10.1021/bm1013316.

[10] H. Ma, K. Yoon, L. Rong, M. Shokralla, A. Kopot, X. Wang, D. Fang, B.S. Hsiao, B. Chu, Thin-film nanofibrous composite ultrafiltration membranes based on polyvinyl alcohol barrier layer containing directional water channels, Ind. Eng. Chem. Res. 49 (2010) 11978-11984, http://dx.doi.org/10.1021/ ie $100545 \mathrm{k}$.

[11] H. Ma, B.S. Hsiao, B. Chu, Functionalized electrospun nanofibrous microfiltration membranes for removal of bacteria and viruses, J. Membr. Sci. 452 (2014) 446-452, http://dx.doi.org/10.1016/j.memsci.2013.10.047.

[12] Y. Zhang, H. Ouyang, T.L. Chwee, S. Ramakrishna, Z.M. Huang, Electrospinning of gelatin fibers and gelatin/PCL composite fibrous scaffolds, J. Biomed. Mater. Res. B 72 (2005) 156-165, http://dx.doi.org/10.1002/jbm.b.30128.

[13] N. Bhardwaj, S.C. Kundu, Electrospinning: A fascinating fiber fabrication technique, Biotech. Adv. 28 (2010) 325-347, http://dx.doi.org/10.1016/j. biotechadv.2010.01.004.

[14] P. Raghavan, D.H. Lim, J.H. Ahn, C. Nah, D.C. Sherrington, H.S. Ryu, H.J Ahn, Electrospun polymer nanofibers: The booming cutting edge technology, React. Funct. Polym. 72 (2012) 915-930, http://dx.doi.org/10.1016/j. reactfunctpolym.2012.08.018.

[15] D.A. Gopakumar, D. Pasquini, M.A. Henrique, L.C. De Morais, Y. Grohens, S. Thomas, Meldrum's acid modified cellulose nanofiber-based polyvinylidene fluoride microfiltration membrane for dye water treatment and nanoparticle removal, ACS Sustain. Chem. Eng. 5 (2017) 2026-2033, http://dx.doi org/10.1021/acssuschemeng.6b02952.

[16] K. Aruchamy, A. Mahto, S.K. Nataraj, Electrospun nanofibers nanocomposites and characterization of art: Insight on establishing fibers as product, Nano-Struct. Nano-Objects. (2018) http://dx.doi.org/10.1016/j.nanoso.2018. 03.013.

[17] Z.M. Huang, Y.Z. Zhang, M. Kotaki, S. Ramakrishna, A review on polymer nanofibers by electrospinning and their applications in nanocomposites, Compos. Sci. Technol. 63 (2003) 2223-2253, http://dx.doi.org/10.1016/ S0266-3538(03)00178-7.

[18] P. Bahmani, A. Maleki, H. Daraei, M. Khamforoush, R. Rezaee, F. Gharibi, A.G. Tkachev, A.E. Burakov, S. Agarwal, V.K. Gupta, High-flux ultrafiltration membrane based on electrospun polyacrylonitrile nanofibrous scaffolds for arsenate removal from aqueous solutions, J. Colloid Interface Sci. 506 (2017) 564-571, http://dx.doi.org/10.1016/j.jcis.2017.07.086.

[19] C.-H. Park, K.-S. Kim, I.-J. Chin, Preparation of electrospun membrane for low-fouling ultrafiltration, PMSE Prepr. 97 (2007) 657-658

[20] Z. Tang, J. Wei, L. Yung, B. Ji, H. Ma, C. Qiu, K. Yoon, F. Wan, D. Fang, B.S. Hsiao, B. Chu, UV-cured poly(vinyl alcohol) ultrafiltration nanofibrous membrane based on electrospun nanofiber scaffolds, J. Membr. Sci. 328 (2009) http://dx.doi.org/10.1016/j.memsci.2008.11.054.

[21] H. Ma, C. Burger, B.S. Hsiao, B. Chu, Ultra-fine cellulose nanofibers: New nano-scale materials for water purification, J. Mater. Chem. 21 (2011) 7507-7510, http://dx.doi.org/10.1039/c0jm04308g.

[22] S. Ramakrishna, K. Fujihara, W.E. Teo, T. Yong, Z. Ma, R. Ramaseshan, Electrospun nanofibers: Solving global issues, Mater. Today 9 (2006) 40-50, http://dx.doi.org/10.1016/S1369-7021(06)71389-X.

[23] S. Zinatloo-Ajabshir, M. Salavati-Niasari, A. Sobhani, Z. Zinatloo-Ajabshir, Rare earth zirconate nanostructures: Recent development on preparation and photocatalytic applications, J. Alloys Compd. (2018) http://dx.doi.org/ 10.1016/j.jallcom.2018.07.198.

[24] S. Zinatloo-Ajabshir, M. Salavati-Niasari, Facile synthesis of nanocrystalline neodymium zirconate for highly efficient photodegradation of organic dyes, J. Mol. Liq. (2017) http://dx.doi.org/10.1016/j.molliq.2017.08.050.

[25] S. Mortazavi-Derazkola, S. Zinatloo-Ajabshir, M. Salavati-Niasari, Facile hydrothermal and novel preparation of nanostructured $\mathrm{Ho}_{2} \mathrm{O}_{3}$ for photodegradation of eriochrome black $\mathrm{T}$ dye as water pollutant, Adv. Powder Technol. (2017) http://dx.doi.org/10.1016/j.apt.2016.11.022.

[26] A. Abbasi, D. Ghanbari, M. Salavati-Niasari, M. Hamadanian, Photodegradation of methylene blue: photocatalyst and magnetic investigation of $\mathrm{Fe}_{2} \mathrm{O}_{3}-\mathrm{TiO}_{2}$ nanoparticles and nanocomposites, J. Mater. Sci., Mater. Electron. (2016) http://dx.doi.org/10.1007/s10854-016-4361-4.

[27] S. Mortazavi-Derazkola, M. Salavati-Niasari, O. Amiri, A. Abbasi, Fabrication and characterization of $\mathrm{Fe}_{3} \mathrm{O}_{4} @ \mathrm{SiO}_{2} @ \mathrm{TiO}_{2} @ \mathrm{Ho}$ nanostructures as a novel and highly efficient photocatalyst for degradation of organic pollution, J. Energy Chem. (2017) http://dx.doi.org/10.1016/j.jechem.2016.10.015.

[28] H. Khojasteh, M. Salavati-Niasari, M.P. Mazhari, M. Hamadanian, Preparation and characterization of $\mathrm{Fe}_{3} \mathrm{O}_{4} @ \mathrm{SiO}_{2} @ \mathrm{TiO}_{2} @ \mathrm{Pd}$ and $\mathrm{Fe}_{3} \mathrm{O}_{4} @ \mathrm{SiO}_{2} @ \mathrm{TiO}_{2} @ \mathrm{Pd}-\mathrm{Ag}$ nanocomposites and their utilization in enhanced degradation systems and rapid magnetic separation, RSC Adv. (2016) http://dx.doi.org/10.1039/c6ra13613c.

[29] M. Mahdiani, F. Soofivand, F. Ansari, M. Salavati-Niasari, Grafting of $\mathrm{CuFe}_{12} \mathrm{O}_{19}$ nanoparticles on CNT and graphene: Eco-friendly synthesis, characterization and photocatalytic activity, J. Clean. Prod. (2018) http: //dx.doi.org/10.1016/j.jclepro.2017.11.177.
[30] S. Zinatloo-Ajabshir, M.S. Morassaei, M. Salavati-Niasari, Facile synthesis of $\mathrm{Nd}_{2} \mathrm{Sn}_{2} \mathrm{O}_{7}-\mathrm{SnO}_{2}$ nanostructures by novel and environment-friendly approach for the photodegradation and removal of organic pollutants in water, J. Environ. Manag. 233 (2019) 107-119, http://dx.doi.org/10.1016/j. jenvman.2018.12.011.

[31] S. Zinatloo-Ajabshir, Z. Salehi, M. Salavati-Niasari, Green synthesis and characterization of $\mathrm{Dy}_{2} \mathrm{Ce}_{2} \mathrm{O}_{7}$ nanostructures using Ananas comosus with high visible-light photocatalytic activity of organic contaminants, J. Alloys Compd. 763 (2018) 314-321, http://dx.doi.org/10.1016/j.jallcom.2018.05. 311.

[32] J. Li, X. Wang, G. Zhao, C. Chen, Z. Chai, A. Alsaedi, T. Hayat, X. Wang, Metal-organic framework-based materials: superior adsorbents for the capture of toxic and radioactive metal ions, Chem. Soc. Rev. (2018) http: //dx.doi.org/10.1039/C7CS00543A.

[33] Y. Wu, H. Pang, Y. Liu, X. Wang, S. Yu, D. Fu, J. Chen, X. Wang, Environmental remediation of heavy metal ions by novel-nanomaterials: A review, Environ. Pollut. 246 (2018) 608-620, http://dx.doi.org/10.1016/ J.ENVPOL.2018.12.076.

[34] P. Gu, S. Zhang, X. Li, X. Wang, T. Wen, R. Jehan, A. Alsaedi, T. Hayat, X. Wang, Recent advances in layered double hydroxide-based nanomaterials for the removal of radionuclides from aqueous solution, Environ. Pollut. (2018) http://dx.doi.org/10.1016/j.envpol.2018.04.136.

[35] G. Zhao, X. Huang, Z. Tang, Q. Huang, F. Niu, X. Wang, Polymer-based nanocomposites for heavy metal ions removal from aqueous solution: A review, Polym. Chem. (2018) http://dx.doi.org/10.1039/c8py00484f.

[36] G. dong Kang, Y. ming Cao, Application and modification of poly(vinylidene fluoride) (PVDF) membranes - A review, J. Membr. Sci. 463 (2014) 145-165, http://dx.doi.org/10.1016/j.memsci.2014.03.055.

[37] F. Liu, N.A. Hashim, Y. Liu, M.R.M. Abed, K. Li, Progress in the production and modification of PVDF membranes, J. Membr. Sci. 375 (2011) 1-27, http://dx.doi.org/10.1016/j.memsci.2011.03.014.

[38] Y. Chang, Y. Shih, R. Ruaan, A. Higuchi, W. Chen, Preparation of poly (vinylidene fluoride) microfiltration membrane with uniform surface- ... J. Membr. Sci. (2007).

[39] Y.J. Byun, J.H. Kim, S.S. Kim, Surface modification of PVDF membranes for water treatment via hydrophilic thermal cross-linking method, Desalination Water Treat. 51 (2013) 5371-5378, http://dx.doi.org/10.1080/ 19443994.2013.768812.

[40] J.G. Choi, T.H. Bae, J.H. Kim, T.M. Tak, A.A. Randall, The behavior of membrane fouling initiation on the crossflow membrane bioreactor system, J. Membr. Sci. (2002) http://dx.doi.org/10.1016/S0376-7388(01)00790-6.

[41] K.H. Choo, C.H. Lee, Membrane fouling mechanisms in the membranecoupled anaerobic bioreactor, Water Res. (1996) http://dx.doi.org/10.1016/ j.physletb.2012.03.002.

[42] S. Gopi, P. Balakrishnan, A. Pius, S. Thomas, Chitin nanowhisker (ChNW)functionalized electrospun PVDF membrane for enhanced removal of Indigo carmine, Carbohydr. Polymers (2017) http://dx.doi.org/10.1016/j. carbpol.2017.02.046.

[43] H.P. Srivastava, G. Arthanareeswaran, N. Anantharaman, V.M. Starov, Performance of modified poly(vinylidene fluoride) membrane for textile wastewater ultrafiltration, Desalination (2011) http://dx.doi.org/10.1016/j. desal.2011.05.054.

[44] N. Nikooe, E. Saljoughi, Preparation and characterization of novel PVDF nanofiltration membranes with hydrophilic property for filtration of dye aqueous solution, Appl. Surf. Sci. (2017) http://dx.doi.org/10.1016/j.apsusc. 2017.04.029.

[45] I. Gancarz, G. Poźniak, M. Bryjak, Modification of polysulfone membranes 1. $\mathrm{CO}_{2}$ plasma treatment, Eur. Polym. J. 35 (1999) 1419-1428, http://dx. doi.org/10.1016/S0014-3057(98)00240-7.

[46] M.L. Steen, L. Hymas, E.D. Havey, N.E. Capps, D.G. Castner, E.R. Fisher, Low temperature plasma treatment of asymmetric polysulfone membranes for permanent hydrophilic surface modification, J. Membr. Sci. 188 (2001) 97-114, http://dx.doi.org/10.1016/S0376-7388(01)00375-1.

[47] M.L. Steen, A.C. Jordan, E.R. Fisher, Hydrophilic modification of polymeric membranes by low temperature water plasma treatment, J. Membr. Sci. 204 (2002) 341-357, http://dx.doi.org/10.1016/S0376-7388(02)00061-3.

[48] C. Yang, M. Tian, Y. Xie, X.M. Li, B. Zhao, T. He, J. Liu, Effective evaporation of $\mathrm{CF}_{4}$ plasma modified PVDF membranes in direct contact membrane distillation, J. Membr. Sci. (2015) http://dx.doi.org/10.1016/j.memsci.2015. 01.059 .

[49] E.S. Kim, Y.J. Kim, Q. Yu, B. Deng, Preparation and characterization of polyamide thin-film composite (TFC) membranes on plasma-modified polyvinylidene fluoride (PVDF), J. Membr. Sci. (2009) http://dx.doi.org/10. 1016/j.memsci.2009.07.036.

[50] L.I. Jiding, C. Jian, C. Cuixian, Surface modification of polyvinylidene fluoride (PVDF) membranes by low-temperature plasma with grafting styrene, Plasma Sci. Technol. (2009) http://dx.doi.org/10.1088/1009-0630/11/1/09.

[51] W.T. Xu, Z.P. Zhao, M. Liu, K.C. Chen, Morphological and hydrophobic modifications of PVDF flat membrane with silane coupling agent grafting via plasma flow for VMD of ethanol-water mixture, J. Membr. Sci. (2015) http://dx.doi.org/10.1016/j.memsci.2015.05.024. 
[52] J. Ju, T. Wang, Q. Wang, Superhydrophilic and underwater superoleophobic PVDF membranes via plasma-induced surface PEGDA for effective separation of oil-in-water emulsions, Colloids Surf. A (2015) http://dx.doi.org/10. 1016/j.colsurfa.2015.01.041.

[53] M. Pascu, D. Nicolas, F. Poncin-Epaillard, C. Vasile, Surface modification of PVDF by plasma treatment for electroless metallization, J. Optoelectron. Adv. Mater. (2006).

[54] M.G. Buonomenna, L.C. Lopez, P. Favia, R. d'Agostino, A. Gordano, E. Drioli, New PVDF membranes: The effect of plasma surface modification on retention in nanofiltration of aqueous solution containing organic compounds, Water Res. (2007) http://dx.doi.org/10.1016/j.watres.2007.06.033.
[55] S. Zhu, S. Jiao, Z. Liu, G. Pang, S. Feng, High adsorption capacity for dye removal by CuZn hydroxyl double salts, Environ. Sci. Nano. (2014) http://dx.doi.org/10.1039/c3en00078h.

[56] Z. Yu, Y. Pan, Y. He, G. Zeng, H. Shi, H. Di, Preparation of a novel antifouling $\beta$-cyclodextrin-PVDF membrane, RSC Adv. (2015) http://dx.doi.org/ 10.1039/c5ra04894j.

[57] Q. Chen, Z. Yu, Y. Pan, G. Zeng H. Shi, X. Yang, F. Li, S. Yang, Y. He, Enhancing the photocatalytic and antibacterial property of polyvinylidene fluoride membrane by blending $\mathrm{Ag}-\mathrm{TiO}_{2}$ nanocomposites, J. Mater. Sci., Mater. Electron. (2017) http://dx.doi.org/10.1007/s10854-016-5999-7.

[58] H. Ma, C. Burger, B.S. Hsiao, B. Chu, Nanofibrous microfiltration membrane based on cellulose nanowhiskers, Biomacromolecules 13 (2012) 180-186, http://dx.doi.org/10.1021/bm201421g. 